\title{
Studies on the genetics of trotting performance in Dutch trotters
}

\section{III. - Estimation of genetic change in speed}

\author{
D. MINKEMA \\ Research Institute for Animal Husbandry «Schoonoord» \\ Driebergseweg $10 \mathrm{D}$, Zeist. \\ the Netherlands
}

\begin{abstract}
Summary
From the performance of Dutch trotters born between 1929 and 1958 the realised annual genetic change in speed has been estimated by means of the regression of performance of full sibs on time. The estimated genetic progress per year was $.479 \pm .360$ seconds per kilometer for time records and $5.39 \pm 3.24$ square root guilders for transformed earnings. Both estimates, although not significantly different from zero, were higher than the annual genetic progress expected from the selection practised, which was .243 seconds for time records and 3.61 square root guilders for transformed earnings. Since the average annual phenotypic improvement in time records was $.307 \pm .028$ seconds per kilometer, it is supposed from the expected genetic progress that 79 p. 100 of the total improvement in speed could have been of genetic origin.

The main part of the genetic progress has been achieved by the selection in males, where the selection percentage was $3.9 \mathrm{p}$. 100. Due to a consistent expansion of the trotter population the selection percentage in females was 92.3 p. 100 only.
\end{abstract}

\section{1. - Introduction}

The speed of trotters in the Netherlands has been improved steadily during the past decades. This progress may partly be attributed to an improvement of the environmental conditions, partly to the effect of selective breeding.

The main environmental changes leading to faster records were the switch from grass tracks to tracks with harder surfaces and the introduction of the automobile starting gate.

Procedures are available to estimate the genetic change in field records from livestock, e.g. by means of comparing the records of close relatives in different years (SMITH, 1962 ; HiLL, 1972). 
This paper deals with the estimation of the genetic change in trotting records of Dutch trotters during the period 1929 to 1958. Also a comparison is made between the realised genetic change and the change expected from the selection procedure practised.

\section{2. - Material and methods}

\section{Data}

The material analysed consisted of life performances of all Dutch trotters born between 1929 and 1958 inclusive, and is also described in a previous paper (Minkema, 1975). The criteria chosen for the analysis of genetic change were :

best time record $=$ fastest time record in minutes and seconds per kilometer, made during the whole trotting career of a trotter

total actual earnings $=$ total amount of money in Dutch guilders, won by a trotter during his whole trotting career.

Both criteria have been corrected for annual fluctuations. The best time record was adjusted by means of taking the deviation from annual trend values, derived from a smooth curve fitted to yearly running means. The earnings were corrected by means of multiplication factors, based on the average amount of money available per trotter starting. Both correction methods have been described previously in detail (Minkema, 1975). Furthermore the performances of male trotters (colts and geldings) have been adjusted to the level of female trotters by means of the average sex differences found. For this purpose time records of male trotters have been increased by 1.14 seconds and their earnings have been decreased by 23.6 p. 100 .

The final analysis of earnings was done on the square root of the corrected total earnings, because this transformation led to a better approximation of the normal distribution of the highly skewed distributed earnings (MINKEMA, 1975) and because the theory of the estimation of the expected genetic change only holds for normal distributed traits.

Horses that died or were exported before their fifth year of age have been excluded from the analysis. Apart from this restriction the analyses based on earnings consisted of all horses, also the non-starters (24.1 p. 100 of all horses). The earnings of non-starters were assumed to be 0 guilders. The analysis of time records only comprised horses that actually trotted and made a record.

\section{Methods}

The method applied to estimate genetic change was the regression of performance of full sibs on time. This method was described by GoodwIN et al. (1955) in poultry as the repeat-mating technique. The change $(\Delta \mathrm{p})$ of the population mean from one year 
to the next is the sum of an environmental change $(\Delta \mathrm{e})$ and a genetic change $(\Delta \mathrm{g})$. Since on average full sibs are genotypically alike, the difference in performance between the younger and the elder full sib (born in subsequent years) only measures the environmental change $(\Delta e)$.

\begin{tabular}{|c|c|c|}
\hline & Year 1 & Year 2 \\
\hline $\begin{array}{c}\text { Full sibs (born in year } 1 \text { and year } 2 \text {, respec- } \\
\text { tively) } \ldots \ldots \ldots \ldots \ldots \ldots \ldots \ldots \ldots \ldots \ldots \ldots\end{array}$ & $y$ & $\mathrm{y}+\Delta \mathrm{e}$ \\
\hline Population mean ... & $\mathbf{x}$ & $\mathrm{x}+\Delta \mathrm{e}+\Delta \mathrm{g}$ \\
\hline Difference $\ldots \ldots \ldots \ldots \ldots \ldots \ldots \ldots \ldots$ & $y-x$ & $y-x-\Delta g$ \\
\hline
\end{tabular}

If the performances of the full sibs are expressed as deviations from their respective contemporaneous population means, the difference between the elder and the younger member of a full sib pair directly yields the genetic change $\Delta \mathrm{g}$.

Since full sibs may be born in years more than one year apart, and since sets of full sibs may comprise more than 2 members, it is more convenient to work with the regression $b_{F S / t}$ of the performance of subsequently born full sibs on time, which regression measures $-\Delta \mathrm{g}$, when the performances are expressed as deviations from their respective population means. This procedure also allows to estimate rather easily a standard error of the genetic change. The regression has been calculated for each set of full sibs, followed by pooling over sets of full sibs. This method, however, only yields unbiased estimates of genetic change if certain conditions are fulfilled. There should be no change in the average age of the parents of the contemporary animals with time. Also the matings to be repeated should not have been selected on the performance of the progeny from the first mating. In the chapter "Results and discussion》 these conditions are discussed in more detail. Furthermore there should be no age change in parental influence on progeny performance. It is unlikely that there is an age influence of the sire on its progeny but there may be a maternal influence. In trotter breeding it is sometimes believed that a heavy trotting career of a mare has a detrimental influence on the performance of her first offspring. On the other hand it could be that older females provide a less favourable influence. Since it is difficult to estimate these maternal influences it is assumed in this study that they were absent.

The average annual phenotypic change $(\Delta \mathrm{p})$ has been estimated by the linear regression $b_{\mathrm{P}^{\prime}}$ of population performance on time.

From the selection procedure practised, the expected genetic change per year $\left(\Delta \mathrm{g}^{*}\right)$ has been estimated according to the method used by RENDEL \& ROBERTSON (1950), 


$$
\Delta g^{*}=\frac{h^{2}{ }_{m} S_{m}+h^{2}{ }_{f} S_{f}}{l_{m}+l_{f}}=\frac{i_{m} h^{2}{ }_{m} \sigma_{m}+i_{f} h^{2}{ }_{f} \sigma_{f}}{l_{m}+l_{f}} \text {, where }
$$

$\mathrm{h}^{2}{ }_{\mathrm{m}}$ and $\mathrm{h}_{\mathrm{f}}{ }_{\mathrm{f}}=$ heritability of trait under study in males (m) and females (f), respectively

$\mathrm{S}_{\mathrm{m}}$ and $\mathrm{S}_{\mathrm{f}}=$ selection differential in males and females, respectively

$i_{m}$ and $i_{f} \quad=$ selection intensity in males and females, respectively

$\sigma_{\mathrm{m}}$ and $\sigma_{\mathrm{f}}=$ standard deviation of trait in males and females, respectively

$l_{m}$ and $l_{f} \quad=$ length of generation interval in males and females, respectively.

\section{3. - Results and discussion}

\section{Phenotypic change in performance}

The average annual phenotypic change in speed during the period 1929 to 1958 has been calculated from the linear regression of the annual population performance on time. The population performance for best time record in a given year was calculated as the mean of the unweighted sex averages.

The regression $b_{\mathrm{Pt}}$ was $-.307 \pm .028$, so the annual phenotypic progress in best time record was .307 seconds. The actual population mean was 1 min. $35.40 \mathrm{sec} / \mathrm{km}$ in $1929(\mathrm{n}=29)$ and $1 \mathrm{~min} .26 .85 \mathrm{sec} / \mathrm{km}$ in $1958(\mathrm{n}=150)$.

\section{Age distribution of parents with time}

If there was any consistent change of the age of the parents of the contemporary animals with time, then the estimate of the genetic change, based on the deviations of performances of individual trotters from the population mean, will be biased upwards or downwards. The average age of the sires of all trotters born between 1929 and 1958 was 15.8 years. Per yearly crop of trotters this average sire age varied between 13.1 years and 19 years, but no trend could be detected. The average age of the dams of all trotters was 12.1 years, with a fluctuation from 11.4 to 13.7 years for the various yearly crops of trotters, but also here no systematic change was detected.

\section{Selection on previous matings}

Repeated matings should not have been carried out on the performance of progeny from the first mating. In the breeding practice of most farm animals there is a tendency to repeat combinations, which proved to be successful.

In order to avoid this preferential mating effect the genetic trend has been estimated from sets of full sibs, with a maximum difference in age of 2 years 
between the youngest and the oldest member. Full sibs, born more than 2 years after the first member, were excluded from the analysis. At the time of mating, giving birth to this younger member, a first indication of the performance of the oldest member could be available, since the training of trotters usually starts between an age of $1 \frac{1}{2}$ and 2 years.

A maximum time span of 2 years between the birth of the youngest and the oldest member of full sib families implies that a set of full sibs can count 2 or 3 animals.

\section{Realised genetic change in performance}

The genetic change per year has been estimated for the whole period 1929-1958 as well as for three separate 10 yearly periods, since it is very unlikely that the genetic change was constant during the whole period of 29 years. The results are given in table 1.

\section{TABLE 1}

Annual genetic change $(\Delta g)$ in best time record (in seconds per kilometer) and in transformed earnings (square root of guilders)

Progrès génétique annuel $(\Delta g)$ pour le temps record (en secondes par kilomètre) et pour les gains transformés (racine carrée des florins néerlandais)

\begin{tabular}{|c|c|c|c|c|c|}
\hline \multirow{2}{*}{ Trait } & & \multicolumn{4}{|c|}{ Period } \\
\hline & & $1929-1940$ & $1939-1950$ & $1949-1958$ & $1929-1958$ \\
\hline \multirow{3}{*}{$\begin{array}{c}\text { Best } \\
\text { time } \\
\text { record }\end{array}$} & $\begin{array}{l}\text { Number of sets of full } \\
\text { sibs } \ldots \ldots \ldots \ldots \ldots \ldots\end{array}$ & 58 & 107 & 142 & 307 \\
\hline & Number of members .. & 128 & 230 & 302 & 660 \\
\hline & $\Delta \mathrm{g} \pm \mathrm{s}(\Delta \mathrm{g})$ (in seconds) & $-.516 \pm .945$ & $-.327 \pm .571$ & $-.591 \pm .521$ & $-.479 \pm .360$ \\
\hline \multirow{3}{*}{$\begin{array}{l}\text { Trans- } \\
\text { formed } \\
\text { earnings }\end{array}$} & $\begin{array}{l}\text { Number of sets of full } \\
\text { sibs } \ldots \ldots \ldots \ldots \ldots \ldots\end{array}$ & 97 & 152 & 181 & 430 \\
\hline & Number of members .. & 214 & 340 & 383 & 937 \\
\hline & $\begin{array}{c}\Delta \mathrm{g} \pm \mathrm{s}(\Delta \mathrm{g}) \text { (in square } \\
\text { root of guilders) } \ldots . .\end{array}$ & $.27 \pm 5.71$ & $8.98 \pm 5.57$ & $5.05 \pm 5.37$ & $5.39 \pm 3.24$ \\
\hline
\end{tabular}

The analysis of earnings includes more horses than the analysis of time records. In the latter case only horses that actually trotted were involved, in the former all horses are included, also non-starters. The genetic change estimated shors a large standard error and in none of the periods studied this change is statistically significant different from zero. In all periods, however, the change means an improvement in performance with time (a negative sign for time record is beneficial). 


\section{Expected genetic change}

From the selection actually practised the expected genetic change could be estimated. Selection on the male side was much more intense than on the female side. A complicating factor was that the majority of the sires used was imported from the U.S.A. or France, so nor their time records nor their earnings were comparable with the performance of sires from Dutch origin. Therefore, the selection intensity on the male side was calculated in two steps. At first the selection intensity was estimated for the sires, bred in the Netherlands and then an adjustment was applied, based on the estimated difference in performance between Dutch and imported sires.

Furthermore, it should be borne in mind that no data of horses before the year 1929 were available. Therefore, only the performance of parents born in 1929 or later could be taken into account. The majority of the progeny of these parents raced in the second and third decade of the total period. So the parameters estimated have in fact relevance to the same period.

The selection intensities on the male and the female side have been estimated from the transformed earnings, because by using earnings in stead of time records also the class of non-starters could be taken into account. But this class, comprising 24.1 p. 100 of all trotters introduced a problem with regard to the distribution of the trait, since the earnings of these horses were fixed to zero guilders.

\section{TABLE 2}

Selection intensity for transformed earnings (square root transformation) in male and female trotters

L'intensité de sélection pour les gains (après transformation racine carrée) dans les trotteurs mâles et femelles

\begin{tabular}{|c|c|c|}
\hline & $\hat{o} \theta$ & $q q$ \\
\hline Population mean $\ldots \ldots \ldots \ldots \ldots \ldots \ldots$ & 97.4 & 82.9 \\
\hline Corrected population mean & 83.5 & 68.2 \\
\hline Parents mean $\ldots \ldots \ldots \ldots \ldots \ldots \ldots \ldots$ & 302.0 (sires) & 90.9 (dams) \\
\hline Corrected parents mean $\ldots \ldots$. & 302.0 (sires) & 83.9 (dams) \\
\hline Selection differential $S_{c} \ldots \ldots \ldots \ldots \ldots$ & 218.5 & 15.7 \\
\hline Standard deviation ... & 87.7 & 79.7 \\
\hline Corrected standard deviation $\sigma_{\mathrm{c}} \ldots \ldots \ldots$ & 109.2 & 99.9 \\
\hline Selection intensity $i_{c}=\frac{S_{c}}{\sigma_{c}} \ldots \ldots \ldots \ldots \ldots$ & 2.001 & .157 \\
\hline
\end{tabular}


So a cluster of 24.1 p. 100 of all trotters was concentrated in the class of 0 guilders, introducing a rather severe discontinuity from normality. However, it was assumed that in fact the distribution of earnings would have been a continuous one if there would have been abundant starting possibilities for trotters. Therefore, also corrected means and standard errors of the transformed earnings were calculated under the assumption that the observations followed a truncated normal distribution. For the derivation of the correction method, see Appendix.

In table 2 the relevant parameters of the transformed earnings are presented.

The uncorrected population means and standard deviations of the transformed earnings of the trotters (including the non-starters) have been published previously (Minkema, 1975). The parents means have been weighted by their number of progeny. These parents means have been corrected also by fitting a truncated normal distribution. In the sires the percentage of non-starters was negligible, in females this percentage was 11.5 p. 100 (hence lower than in the total population, where it was 24.1 p. 100). It was assumed that the non-starting dams were a random sample from the class of non-starting trotters.

TABLE 3

I.N.R.A. - C.N.R.2. F 78350 JOUY EN JOSAS

Expected genetic progress per year $\left(\Delta g^{*}\right)$ for time records and transformed earnings

Progrès génétique annuel attendu $\left(\Delta g^{*}\right)$ pour le temps record et les gains transformés

\begin{tabular}{|c|c|c|c|c|}
\hline & \multicolumn{2}{|c|}{ Time records } & \multicolumn{2}{|c|}{ Transformed earnings } \\
\hline & o ô & q $q$ & ô $\hat{\sigma}$ & 우우 \\
\hline Adjusted selection intensity $\ldots \ldots \ldots \ldots \ldots$ & 2.165 & .157 & 2.165 & .157 \\
\hline Corresponding selection percentage $\mathrm{p} \ldots \ldots$ & $3.9 \%$ & $92.3 \%$ & $3.9 \%$ & $92.3 \%$ \\
\hline Heritability $\ldots \ldots \ldots \ldots \ldots \ldots \ldots \ldots \ldots$ & .36 & .36 & .40 & .40 \\
\hline Standard deviation $\ldots \ldots \ldots \ldots \ldots$ & 8.1 & 8.4 & 87.7 & 79.7 \\
\hline Corrected standard deviation & & & 109.2 & 99.9 \\
\hline Generation length $\ldots \ldots \ldots \ldots \ldots$ & 15.8 & 12.1 & 15.8 & 12.1 \\
\hline Total selection response per year $\left(\Delta g^{*}\right) \ldots$ & \multicolumn{2}{|c|}{.243 seconds } & \multicolumn{2}{|c|}{$\begin{array}{l}3.61 \text { square root } \\
\text { guilders }\end{array}$} \\
\hline
\end{tabular}

The selection intensity of 2.001 in the males is an incorrect estimation, because it is based on Dutch sires only. Imported stallions (mainly from the U.S.A. and France) sired 80.6 p. 100 of the progeny. Many of these stallions also trotted in the Netherlands in the later part of their trotting career and made a time record. Weighted for their number of progeny, the average time record of the imported and of the Dutch sires was 10.17 seconds and 8.25 seconds respectively better than the contemporary population mean of male trotters. Since the standard deviation of time records in male trotters was 8.1 seconds, the foreign sires were $.237 \sigma$ better 
than the Dutch ones, yielding an adjusted selection intensity in males of 2.165. The selection intensities calculated in this way have been used to estimate the expected genetic progress per year for time records and transformed earnings. The parameters necessary for this calculation are summarized in table 3. Heritabilities, standard deviations and generation lengths have been derived from an earlier study (MINKEMA, 1975). The heritabilities are the average of the values found for each sex separately.

The genetic progress expected is lower than the calculated realized progress, but it should be borne in mind that the latter estimate has a very large standard error. For the time records both figures are .243 and .479 seconds, respectively, and for transformed earnings 3.61 and 5.39 square root guilders, respectively.

Since the total change in speed per year was .307 seconds, an expected genetic progress of .243 seconds per year means that 79 p. 100 of the total improvement could be of genetic origin, leaving 21 p. 100 to be attributed to the improvement in environment. For earnings no total change can be estimated, since the total amount of purse money available per year depends upon economic circumstances and has no direct relation with genetic or environmental factors.

The conclusion seems to be justified that during the period 1929 to 1958 a real genetic progress in speed has been realised in Dutch trotters. It is obvious that the main part of this progress has to be attributed to the selection practised on males, since the best 3.9 p. 100 of the males was used for breeding. In females the selection percentage was only 92.3 p. 100 (see table 3). The reason for this weak selection in females is that the trotter population has expanded consistently during the period under investigation. In 1929 the number of foals born was 44, in 1955 this number was 190 . If the trotter population should remain stable numerically, it will be possible to select much stronger on the female side. In a stable situation a selection percentage between 40 p. 100 and 50 p. 100 could be reached in females, depending upon the foaling percentage and the length of the breeding career, which in turn depends upon the average length of the trotting career and life expectation.

Reçu pour publication en juillet 1981.

\section{Acknowledgements}

For each of the three contributions in this series the author is much indebted to the Institute T.N.O. for Mathematics, Information processing and Statistics in Wageningen and to Ir. A.A.M. JANSEN for their assistance in the statistical treatment of the data. The «Stichting Nederlandse Draf- en Rensport » in The Hague is thanked for providing the data of Dutch trotters and for its financial support, the «Stichting Nederlandse Veefokkerij» in The Hague for its financial support as well. The author is also much indebted to Dr. B. LangloIs (I.N.R.A., Jouy-en-Josas, France) for his critical reading of the manuscript of the last contribution in this series. 


\section{Résumé \\ Etudes génétiques des performances du Trotteur hollandais \\ III. - Estimation du progrès génétique sur la vitesse}

Le progrès génétique annuel réalisé sur les performances en course des Trotteurs Hollandais nés de 1929 à 1958 a été estimé par la régression des performances de plein frères et sœurs sur l'année.

Cette estimation était de $0,479 \pm 0,360$ seconde pour le temps record au kilomètre et de $5,39 \pm 3,24$ pour la racine carrée du gain (en florins néerlandais). Ces deux estimations, bien que non significativement différentes de zéro, sont supérieures à l'espérance du progrès génétique annuel attendu de la sélection effectuée, qui est de 0,243 seconde pour le temps record et de 3,61 florins néerlandais transformés pour les gains.

Puisque le progrès phénotypique annuel réalisé sur le temps record était estimé à $0,307 \pm 0,028$ secondes, on peut supposer, à cause de l'espérance du progrès génétique que 79 p. 100 du progrès total est probablement d'origine génétique. Cela est dû essentiellement au choix des étalons dont le taux de sélection a été estimé à 3,9 p. 100 alors que le même paramètre estimé chez les poulinières n'est que de 92,3 p. 100 en raison de l'expansion numérique de la population des Trotteurs Hollandais au cours de la période étudiée.

\section{References}

Cochran W.G., 1951. Improvement by means of selection. Proc. Second Berkeley Sym. Math. Stat. Prob., 449-470.

Goodwin K., Dickerson G.E. and Lamoreux W.F., 1955. A technique for measuring genetic progress in poultry breeding experiments. Abstr. in Poult. Sci., 34, 1197.

HILl W.G., 1972. Estimation of genetic change. I. - General theory and design of controI populations. Anim. Breed. Abstr., 40, 1-15.

Minkema D., 1975. Studies on the genetics of trotting performance in Dutch Trotters. I. - The heritability of trotting performance. Ann. Génét. Sél. anim., 7, 99-121.

Pearson K., 1903. On the influence of natural selection on the variability and correlation of organs. Phil. Trans., A 200, 1-66.

RENDEL J.M. and Robertson A., 1950. Estimation of genetic gain in milk yield by selection in a closed herd of dairy cattle. J. Genet., 50, 1-8.

Smith C., 1962. Estimation of genetic change in farm livestock using field records. Anim. Prod., 4, 239-251.

\section{Appendix}

Adjustment for the truncation of a normal distribution at $\mathrm{x}=0$ and the clustering of the truncated tail in the point of truncation.

Let $\mathrm{x}^{*}$ be distributed $\mathrm{N}(\xi, \sigma)$ and let $\mathrm{x}$ be distributed according to the rules :

$$
\begin{array}{lll}
x=0 & \text { if } & x^{*} \leqslant 0 \\
x=x^{*} & \text { if } & x^{*}>0
\end{array}
$$


Let the ordinate of the frequency function of $x^{*}$ at $x^{*}=0$ be denoted by $z$, and the probability $P\left(x^{*}>0\right)$ be denoted by $p$. Then for the mean and the variance of the truncated distribution the following expressions hold (PEARSON, 1903 ; Cochran, 1951):

$$
\begin{aligned}
& \mathrm{E}\left(\mathrm{x}^{*} \mid \mathrm{x}^{*}>0\right)=\xi+\mathrm{i} \sigma \\
& \operatorname{var}\left(\mathrm{x}^{*} \mid \mathrm{x}^{*}>0\right)=\left(1-\mathrm{i} \xi ; \sigma-\mathrm{i}^{2}\right) \sigma^{2} \\
& \text { where } \mathrm{i}=\mathrm{z} / \mathrm{p}
\end{aligned}
$$

Expectation and variance of $\mathrm{x}$ may be easily derived by using the well-known relations between conditional and unconditional moments :

$$
\begin{aligned}
& \mathrm{Ex}=\mathrm{E}_{\mathrm{A}} \mathrm{E}(\mathrm{x} \mid \mathrm{A}) \\
& \operatorname{var} \mathrm{x}=\mathrm{E}_{\mathrm{A}} \operatorname{var}(\mathrm{x} \mid \mathrm{A})+\operatorname{var}_{\mathrm{A}} \mathrm{E}(\mathrm{x} \mid \mathrm{A})
\end{aligned}
$$

The conditioning variate $\mathrm{A}$ may be chosen in such a way that it discriminates between the sets of $x$-values $\{x=0\}$ and $\{x>0\}$.

One obtains :

$$
\begin{aligned}
& \mathrm{Ex}=\mathrm{p}(\xi+\mathrm{i} \sigma) \\
& \operatorname{var} \mathrm{x}=\mathrm{p} \sigma^{2}-\mathrm{pi} \sigma(\xi+\mathrm{i} \sigma)+\mathrm{p}(1-\mathrm{p})(\xi+\mathrm{i} \sigma)^{2}
\end{aligned}
$$

After substituting estimates $\overline{\mathrm{x}}$ for $\mathrm{Ex}$ and $\mathrm{s}^{2}$ for var $\mathrm{x}$, the resulting equations can be solved for $\xi$ and $\sigma$. This provides the explicit expressions for the adjustment of the estimates :

$$
\begin{aligned}
& \dot{\sigma}=\left(\mathrm{i} \overline{\mathrm{x}}+\sqrt{ }\left\{(\mathrm{i} \overrightarrow{\mathrm{x}})^{2}-4(1-\mathrm{p}) \overrightarrow{\mathrm{x}}^{2}+4 \mathrm{ps}^{2}\right\}\right) / 2 \mathrm{p} \\
& \hat{\xi}=\overrightarrow{\mathrm{x}} / \mathrm{p}-\mathrm{i} \hat{\sigma}
\end{aligned}
$$

